\title{
Trop2 is a potential biomarker for the promotion of EMT in human breast cancer
}

\author{
WEI ZHAO $^{1^{*}}$, XINGWANG KUAI ${ }^{2 *}$, XUEYI ZHOU ${ }^{3}$, LIZHOU JIA $^{2}$, JINSONG WANG $^{1}$, XIAOBING YANG $^{1}$, \\ ZHIDAN TIAN $^{1}$, XIAOLEI WANG ${ }^{1}$, QIAN LV $^{1}$, BIN WANG $^{1}$, YOUCAI ZHAO ${ }^{1}$ and WENBIN HUANG ${ }^{1}$ \\ ${ }^{1}$ Department of Pathology, Nanjing First Hospital, Nanjing Medical University, Nanjing, Jiangsu 210006; \\ ${ }^{2}$ Department of Pathology, Nanjing Medical University, Nanjing, Jiangsu 210029; \\ ${ }^{3}$ Department of Oncology, Huai'an Hospital Affiliated of Xuzhou Medical College and Huai'an Second People's Hospital, \\ Huai'an, Jiangsu 223002, P.R. China
}

Received December 19, 2017; Accepted May 31, 2018

DOI: 10.3892/or.2018.6496

\begin{abstract}
Trop2 is considered to have an important function in tumor metastasis and the promotion of epithelial-mesenchymal transition (EMT). E-cadherin is a crucial factor in intercellular adhesion and EMT transformation. In the present study, we detected the expression of Trop2 and E-cadherin in breast cancer $(\mathrm{BC})$ to better define their prognostic value. The mRNA expression levels of these two genes in 20 cases of fresh $\mathrm{BC}$ tissues were detected by quantitative real-time polymerase chain reaction (qRT-PCR). We also detected the expression levels of these two genes by immunohistochemistry (IHC) in $312 \mathrm{BC}$ tissues, and the correlations between the expression of these two genes and the clinicopathological characteristics in $\mathrm{BC}$ patients were analyzed. The mRNA and protein expression levels of the two genes in $\mathrm{BC}$ cell lines were studied by qRT-PCR and western blotting. The results indicated that Trop2 ${ }^{+} / \mathrm{E}$-cadherin ${ }^{-}$was expressed in $\mathrm{BC}$ tissues more than that in the matched adjacent tissues. The protein expression results obtained via IHC were similar to the mRNA expression results. Trop2 ${ }^{+} / \mathrm{E}$-cadherin ${ }^{-}$that was expressed in $\mathrm{BC}$ was associated with lymph node status, metastasis, tumor-node-metastasis (TNM) stage, and ER $/ \mathrm{PR}^{-} / \mathrm{HER} 2{ }^{-}$expression. $\mathrm{BC}$ patients that expressed Trop2 ${ }^{+} / \mathrm{E}$-cadherin ${ }^{-}$had poor overall survival rates. The results of Trop2 and E-cadherin expression levels obtained in the $\mathrm{BC}$ cell lines were the same as those obtained in the $\mathrm{BC}$ tissues. Overall, Trop2 has a potential role in the promotion of EMT in BC and it could be considered as a therapeutic target in the future.
\end{abstract}

Correspondence to: Dr Wenbing Huang or Dr Youcai Zhao, Department of Pathology, Nanjing First Hospital, Nanjing Medical University, 68 Changle Road, Nanjing, Jiangsu 210006, P.R. China

E-mail: wbhuang348912@126.com

E-mail: 13852293317@163.com

${ }^{*}$ Contributed equally

Key words: Trop2, E-cadherin, breast cancer, EMT, prognostic

\section{Introduction}

$\mathrm{BC}$ is the second leading cause of cancer-related deaths in women after lung cancer and it accounts for nearly $25 \%$ of all cancers in females $(1,2)$. Approximately 1.4 million women worldwide are diagnosed with $\mathrm{BC}$ each year, and half a million $\mathrm{BC}$ patients succumb to the disease (3). $\mathrm{BC}$, which is comprised of several different phenotypes, is a highly heterogeneous disease (4). According to studies $(1,2)$, based on the analysis of the expression of estrogen receptor (ER), progesterone receptor (PR), human epidermal growth factor receptor 2 (HER2), and $\mathrm{Ki}-67, \mathrm{BC}$ is classified into five subtypes, including luminal A, luminal B, normal breast-like, HER2 and basal-like. One of these subtypes, triple negative breast cancer (TNBC), is defined by the lack of ER, PR and HER2 expression in tumor tissues, and it accounts for $15-23.8 \%$ of BC patients (5). Compared with the other subtypes, TNBC is frequently found in premenopausal women, particularly in young women $(<50$ years), who may have a higher grade and a higher rate of a cellular tumor antigen p53 mutation (6). TNBC is more prevalent in African-American women and more aggressive than other molecular subtypes of breast tumors (7). Although the risk and roles of ER-positive cancer are well defined, those for TNBC are not as well defined. Therefore, it is critical to understand gene expression and genetic variability in the etiology and pathogenesis of these types of BC.

Human trophoblast cell surface protein 2 (Trop2/ TACSTD2/M1S1/GA733-1), is a 36-kDa transmembrane protein that is expressed primarily in the membrane surface of epithelial cells (8). Trop2 has been revealed to affect tumor proliferation, metastasis and invasion as an oncogene, and it is overexpressed in various epithelial tumors, which may be associated with aggressive tumor effects (9-12). In our previous study, we found that Trop2 has an important role in regulating stem cells and inducing EMT of gastric cancer cells. However, little is known about the regulatory role of Trop2 in TNBC.

E-cadherin is a type of adhesion molecule that mainly exists in human and animal epithelium, and its main function is to maintain normal epithelial cell morphology and structural integrity (13-15). E-cadherin can regulate the close adhesion of epithelial cells and its downregulation is a key factor in 
epithelial neoplasm development (16). The aberrant structure of E-cadherin was found in tumor cells, and the adhesion ability of cells was decreased, which could easily lead to infiltration and distal metastasis of cells to peripheral tissues (17). E-cadherin has been considered to be an important component of intercellular adhesion and it is also a key factor in initiating EMT transformation $(18,19)$. Decreased E-cadherin expression in cancers, which could induce the EMT phenomenon has been a popular research area in recent years (20). Many researchers have found that inhibiting E-cadherin expression could be related to the differentiation, invasion and metastasis of tumors $(21,22)$.

In the present study, we examined the relationship between Trop2 and E-cadherin in BC tissues obtained from Chinese patients and compared the expression of two genes in the $\mathrm{BC}$ tissues with matched adjacent non-tumor tissues.

\section{Materials and methods}

Tissue sample and clinical information. We studied a cohort of 312 patients who were diagnosed with primary BC from January 2009 to December 2012. A total of 354 formalin-fixed, paraffin-embedded (FFPE) BC tissue samples were investigated, including $B C$ tissues $(n=295)$ and matched adjacent tissues $(n=59)$. All of the tissue blocks were obtained from the Department of Pathology, Nanjing First Hospital. Clinical information about the tissues was collected, including age, location, tumor size, tumor-node-metastasis (TNM) stage, ER/PR/HER2 status, Ki-67 expression, histological grade, lymph node status, metastasis and overall survival (OS). In addition, 20 pairs of freshly frozen BC tissues were obtained from the Department of Pathology, Nanjing First Hospital. Written informed consent was obtained before the patients underwent surgery. All the results obtained from the study will have no effect on the patient's health and future treatment. The study protocol was approved by the Human Research Ethic Committee of Nanjing First Hospital.

$q R T-P C R$. We detected Trop2 and E-cadherin mRNA expression levels in 20 pairs of human BC tissues, and then we compared them with matched adjacent tissues. Cell RNA was extracted with TRIzol reagent (Invitrogen; Thermo Fisher Scientific, Inc., Waltham, MA, USA) and then reverse-transcribed into cDNA using a PrimeScript ${ }^{\mathrm{TM}}$ RT reagent kit (Takara Bio, Inc., Otsu, Japan) according to the manufacturer's protocol. Human GAPDH served as the internal control. The primers used in the study were asfollows: GAPDH forward, 5'-GAAGGTGAAGGTCGGAGTC-3' and reverse, 5'-GAA GATGGTGATGGGATTTC-3'; Trop2 forward, 5'-TGTCCT GATGTGATATGTCTGAG-3' and reverse, 5'-GGGTGAGAG TGGGTTGGG-3'; E-cadherin forward, 5'-GACGCGGAC GATGATGTGAAC-3' and reverse, 5'-TTGTACGTGGTG GGATT GAAG-3' (GenScript Co., Ltd., Nanjing, China). qRT-PCR was performed on an ABI Prism 7500 HT Sequence Detection System (Applied Biosystems; Thermo Fisher Scientific, Inc.) in 96-well plates. Relative expression levels were calculated as ratios normalized against those of GAPDH. Results were normalized to the respective internal controls. The Ct-value for each sample was calculated using the $\Delta \Delta \mathrm{Ct}$ method, and the results were expressed as $2^{-\Delta \Delta C t}$.
Tissue microarray (TMA) construction and IHC. The TMAs were constructed at the Department of Pathology, Nanjing First Hospital, (Nanjing, China) using the Quick-Ray tissue system (Unitma, Co., Ltd., Seoul, Korea) manual. Core tissue biopsies ( $2 \mathrm{~mm}$ in diameter) were obtained from 60 individuals. FFPE blocks were made and then arranged in new recipient paraffin blocks. A total of 5 breast TMAs were created. Tissue sections were deparaffinized and rehydrated through graded alcohols. Endogenous peroxidase activity was blocked by incubation in $3 \% \mathrm{H}_{2} \mathrm{O}_{2}$. Tissues were then placed in $0.01 \mathrm{M}$ citrate buffer (pH 6.0), and heated in a microwave for antigen retrieval. Trop2 was detected using a monoclonal antibody rabbit anti-human Trop2 (dilution 1:100) (cat. no. ab227689; Abcam, Cambridge, UK), and a monoclonal antibody mouse anti-human E-cadherin (dilution 1:100; cat. no. sc-8426; Santa Cruz Biotechnology, Inc., Dallas, TX, USA). Reactions were detected with an EnVision $^{\mathrm{TM}}$ peroxidase kit (Dako; Agilent Technologies, Inc., Santa Clara, CA, USA). Tissues were then incubated in 3,3'-diaminobenzidine (Dako; Agilent Technologies, Inc.), counterstained with hematoxylin, dehydrated through graded alcohols, cleared in xylene, and coverslipped with permanent mounting media. Staining was quantified in all of the tissues without knowledge of clinical characteristics. Trop2 expression was scored using the semi-quantitative $\mathrm{H}$-score method, which takes into account both the staining intensity and the percentage of cells at that intensity (8). The following staining intensity scores were used: 0 indicated no staining; $1+$ indicated weak staining; $2+$ indicated moderate staining; and $3+$ indicated intense staining. The total number of cells at each intensity level was multiplied by the corresponding intensity score to yield an intensity percentage score. Final staining scores were then calculated by summing the four intensity percentage scores; the minimum possible final staining score was 0 (no staining) and the maximum possible score was 300 (100\% of cells with $3+$ staining intensity).

Cell lines and cell culture. The human BC cell lines MCF-7 and MDA-MB-231 and the human breast epithelial cell line MCF-10A were preserved in our laboratory. Cell lines were maintained at $37^{\circ} \mathrm{C}$ in RPMI-1640 medium with $10 \%$ fetal bovine serum and $1 \%$ penicillin-streptomycin (all from Gibco; Thermo Fisher Scientific, Inc). A humidified atmosphere containing $5 \% \mathrm{CO}_{2}$ was used to incubate the cells.

Protein extraction and western blot analysis. Intracellular proteins were extracted using RIPA Lysis and Extraction Buffer (Thermo Fisher Scientific, Inc.) based on the manufacturer's protocol. Protein concentrations were determined using a BCA Protein Assay kit (Beyotime Institute of Biotechnology, Haimen, China). The same amounts of protein were resolved by $10 \%$ SDS-PAGE and transferred to a polyvinylidene difluoride (PVDF) membrane. The membrane was blocked for $1 \mathrm{~h}$ and then incubated with primary antibodies (anti-Trop2 antibody or anti-E-cadherin antibody) overnight at $4^{\circ} \mathrm{C}$. After washing three times with PBS-Tween-20 (PBST), the membrane was incubated with secondary antibodies, including HRP-goat anti-rabbit secondary antibody (cat. no. A12004-1; Amy Jet Scientific, Wuhan, China), HRP-goat anti-mouse secondary antibody (A12003-1; Epigentek, Farmingdale, NY, USA) at room temperature for $1 \mathrm{~h}$. The membrane was subsequently 
Table I. Trop2 and E-cadherin expression in breast cancer tissues.

\begin{tabular}{|c|c|c|c|c|c|c|c|c|}
\hline Characteristics & $\mathrm{n}$ & $\begin{array}{c}\text { Trop2 } \\
\text { E-cadherin }\end{array}$ & $\begin{array}{c}+ \\
+ \\
(\%)\end{array}$ & $\begin{array}{c}+ \\
- \\
(\%)\end{array}$ & $\begin{array}{c}- \\
+ \\
(\%)\end{array}$ & $\begin{array}{c}- \\
- \\
(\%)\end{array}$ & $\begin{array}{c}\text { Pearson } \mathrm{x}^{2} \\
37.105\end{array}$ & $\begin{array}{l}\text { P-value } \\
<0.001^{\text {a }}\end{array}$ \\
\hline TNBC tissue & 96 & & $7(7.3)$ & $68(70.8)$ & $16(16.7)$ & $5(5.2)$ & & \\
\hline $\mathrm{BC}$ tissue & 199 & & $22(11.1)$ & $102(51.3)$ & $61(30.7)$ & $14(7.0)$ & & \\
\hline Matched adjacent tissue & 59 & & $8(13.6)$ & $13(22.0)$ & $28(47.5)$ & $10(16.9)$ & & \\
\hline
\end{tabular}

+ , Represents high expression and -, represents low expression or no expression ${ }^{\mathrm{a}} \mathrm{P}<0.001$. TNBC, triple negative breast cancer; $\mathrm{BC}$, breast cancer.

washed with PBST and incubated with SuperSignal West Pico PLUS Chemiluminescent Substrate (Thermo Fisher Scientific, Inc.) for $5 \mathrm{~min}$. The specific bands were exposed to the ChemiDoc XRS+ System (Bio-Rad Laboratories, Inc., Hercules, CA, USA). The expression of GAPDH was used as the internal control.

Statistical analysis. The SPSS 19.0 statistical software package (SPSS, Inc., Chicago, IL, USA) was utilized to analyze all of the statistics. Unpaired Student's t-test was performed to compare two groups. One-way ANOVA followed by Tukey's multiple comparison test was used when three or more groups were compared. $\chi^{2}$ tests were performed to evaluate whether the expression levels of Trop2 and E-cadherin were associated with clinicopathological parameters. Kaplan-Meier analysis was used to estimate cumulative patient survival. Survival curves were compared by log-rank test. $\mathrm{P}<0.05$ was considered to indicate a statistically significant result.

\section{Results}

Trop2 and E-cadherin mRNA expression in BC tissues compared with matched adjacent tissues. To study the levels of Trop2 and E-cadherin mRNA, we used qRT-PCR in 20 pairs of $\mathrm{BC}$ tissues and matched adjacent tissues. Trop2 and E-cadherin mRNA expression levels in BC tissues were $1.55 \pm 0.78$ and $0.70 \pm 0.38$ fold higher than those in the matched adjacent tissues, respectively $(\mathrm{P}=0.018)$. Notably, we also found Trop2 and E-cadherin mRNA expression levels in the TNBC tissues (T6, 9, 11, 12, 15, 16, 19 and 20) were $2.76 \pm 0.77$ $(\mathrm{P}=0.013)$ and $0.54 \pm 0.21(\mathrm{P}=0.010)$ fold higher than those in other types of $\mathrm{BC}(\mathrm{T} 1,2,3,4,5,7,8,10,13,14,17$ and 18, respectively) (Fig. 1).

Trop2 and E-cadherin protein expression in BC tissues compared with matched adjacent tissues. We used an IHC assay to detect Trop2 and E-cadherin protein expression levels in BC tissues, and we found that Trop2 and E-cadherin were localized at the membrane and cytoplasm of the $\mathrm{BC}$ cells (Fig. 2). Trop2 was overexpressed in the $\mathrm{BC}$ tissues, while E-cadherin had a low expression in BC tissues. We defined high and low Trop2/E-cadherin expression levels based on OS in $\mathrm{BC}$ patients through the $\mathrm{x}$-tile software program for TMA data analysis. For Trop2, the cut-off of 130 was selected, and

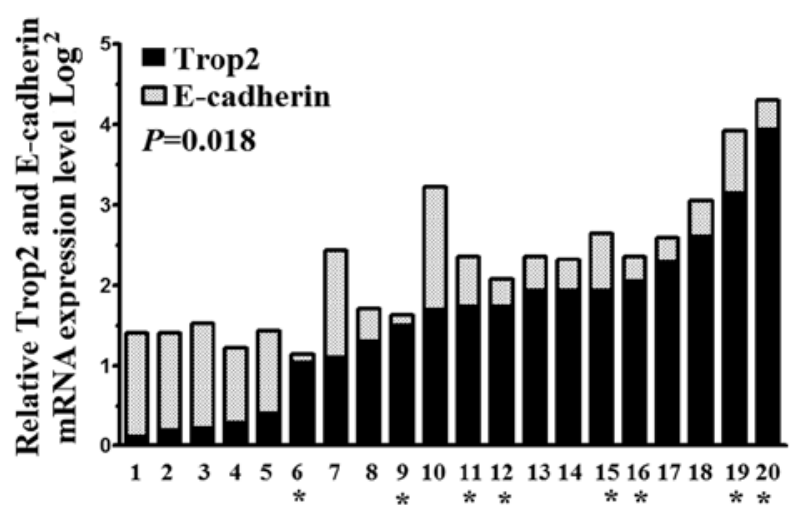

Figure 1. Trop2 and E-cadherin mRNA expression in 20 pairs of breast cancer tissues. Trop2 and E-cadherin mRNA expression was detected by qRT-PCR and normalized to GAPDH. The * represents TNBC tissue. qRT-PCR, quantitative real-time polymerase chain reaction; TNBC, triple negative breast cancer.

a score of 0-130 was considered to be low or no expression, while 131-300 was considered to be a high expression. For E-cadherin, a score of $0-120$ was considered to be low or no expression, while 121-300 was considered to be a high expression.

High Trop2 and high E-cadherin $\left(\mathrm{T}^{4} \mathrm{E}^{+}\right)$, high Trop2 and low E-cadherin $\left(\mathrm{T}^{4} \mathrm{E}^{-}\right)$, low Trop2 and high E-cadherin $\left(\mathrm{TE}^{+}\right)$, and low Trop2 and low E-cadherin (TE-) expression was detected in the $\mathrm{BC}$ tissues, compared with those in the matched adjacent tissues. The levels of $\mathrm{T}^{4} \mathrm{E}^{+}, \mathrm{T}^{4} \mathrm{E}^{-}, \mathrm{TE}^{+}$and $\mathrm{TE}^{-}$expression in the TNBC tissues were 7 (7.3\%), 68 (70.8\%), 16 (16.7\%), and $5(5.2 \%)$, while in the BC tissues, they were $22(11.1 \%)$, $102(51.3 \%), 61(30.7 \%)$, and 14 (7.0\%), and compared with those in matched adjacent tissues, they were $8(13.6 \%)$, $13(22.0 \%), 28(47.5 \%)$, and $10(16.9 \%)$, respectively $\left(\chi^{2}=37.105\right.$, $\mathrm{P}<0.001)($ Table I).

Association of Trop 2 and $E$-cadherin expression with clinicopathological characteristics in BCs. Next, we investigated the relationship between Trop2/E-cadherin protein expression and clinicopathological variables in tissues of $\mathrm{BC}$ patients. The results indicated that the $\mathrm{T}^{+} \mathrm{E}^{-}$expression in $\mathrm{BC}$ was associated with lymph node status $\left(\chi^{2}=36.688, \mathrm{P}<0.001\right)$, metastasis $\left(\chi^{2}=42.958, P<0.001\right)$, TNM stage $\left(\chi^{2}=15.91, P<0.014\right)$, and TNBC $\left(\chi^{2}=10.429, \mathrm{P}<0.015\right)$. However, we did not detect a 
$\mathbf{A}_{\mathbf{a}}$

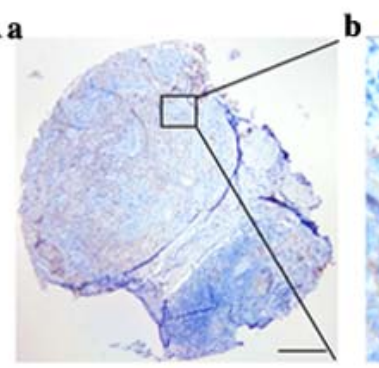

b

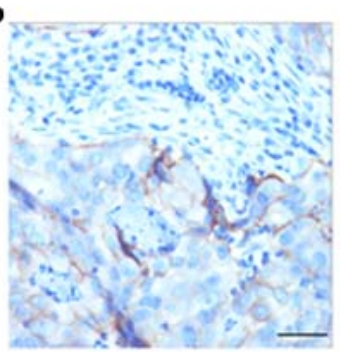

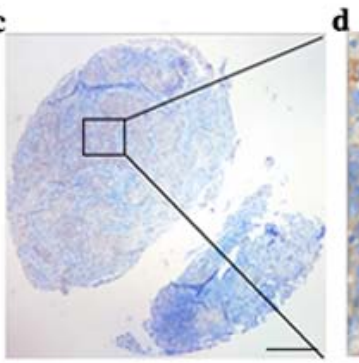
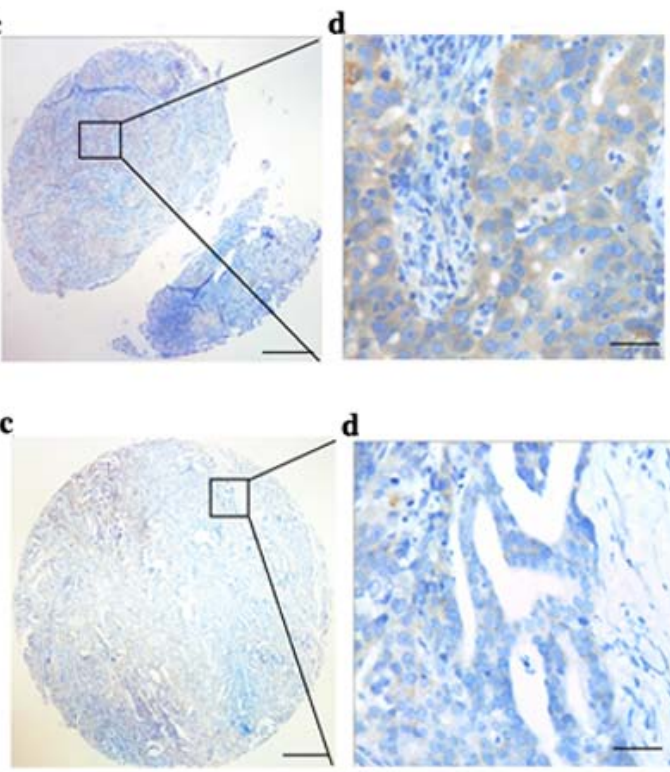

c

d

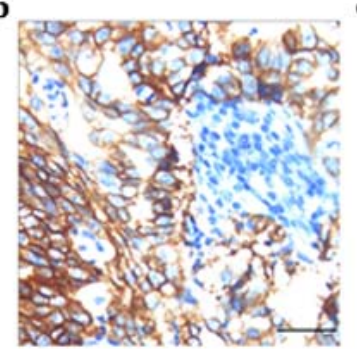

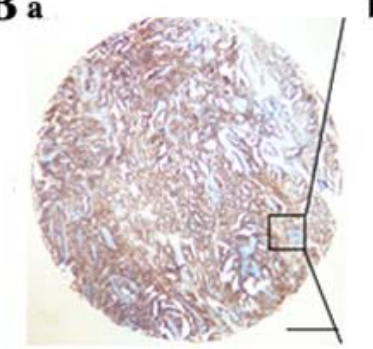

Figure 2. Representative pattern of Trop2 and E-cadherin protein expression in BC tissues on TMA sections. (A-a and b) Low expression of Trop2 in matched adjacent tissues (IHC score, 80); (A-c and d) high expression of E-cadherin in matched adjacent tissues (IHC score, 180); (B-a and b) high expression of Trop2 in BC tissues (IHC score, 300); and (B-c and d) low expression of E-cadherin in BC tissues (IHC score, 50). Row a and c are Trop2/E-cadherin staining with x4 (bar, $500 \mu \mathrm{m}$ ), and row b and d are Trop2/E-cadherin staining with x40 (bar, $50 \mu \mathrm{m}$ ). BC, breast cancer; IHC, immunohistochemistry; TMA, tissue microarray.

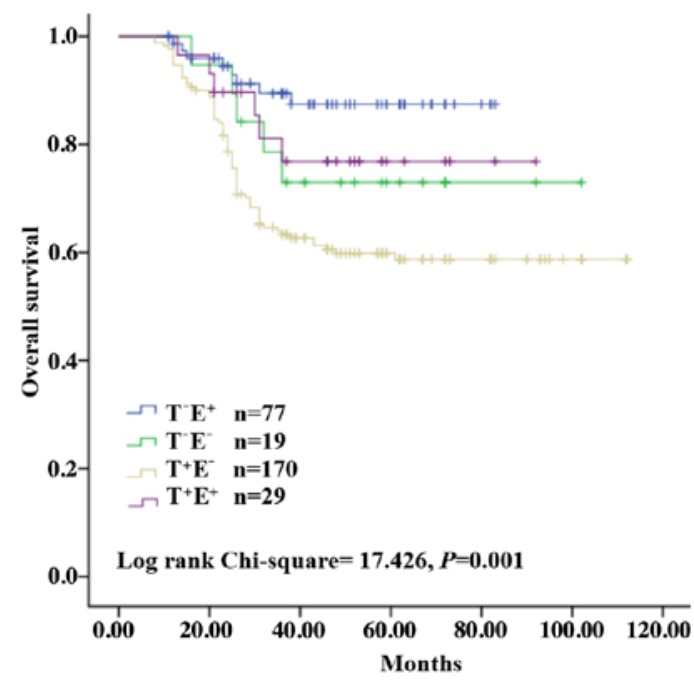

Figure 3. Survival curves for breast cancer using the Kaplan-Meier method and log-rank test. Overall survival curves for patients with Trop2-E-cadherin ${ }^{+}$ (blue line, 1), Trop2-E-cadherin (green line, 2), Trop2 ${ }^{+} \mathrm{E}$-cadherin ${ }^{-}$(khaki line, 3), and Trop2 ${ }^{+} \mathrm{E}-$ cadherin $^{+}$(purple line, 4 ).

significant association between Trop2 and E-cadherin expression levels and tumor location, age and tumor size (Table II).

Prognostic value of Trop2 and E-cadherin protein expression in $B C$. We also used univariate and multivariate analyses to examine the possible prognostic factors for BC. The results revealed that $\mathrm{T}^{+} \mathrm{E}^{-}$expression was significantly associated with a shorter survival in univariate analysis, along with lymph node status, metastasis, TNM stage and TNBC. Multivariate analysis further indicated that $\mathrm{T}^{+} \mathrm{E}^{-}$expression was associated with poor OS, as did lymph node status, metastasis and TNBC (Table III). Kaplan-Meier survival curves revealed that

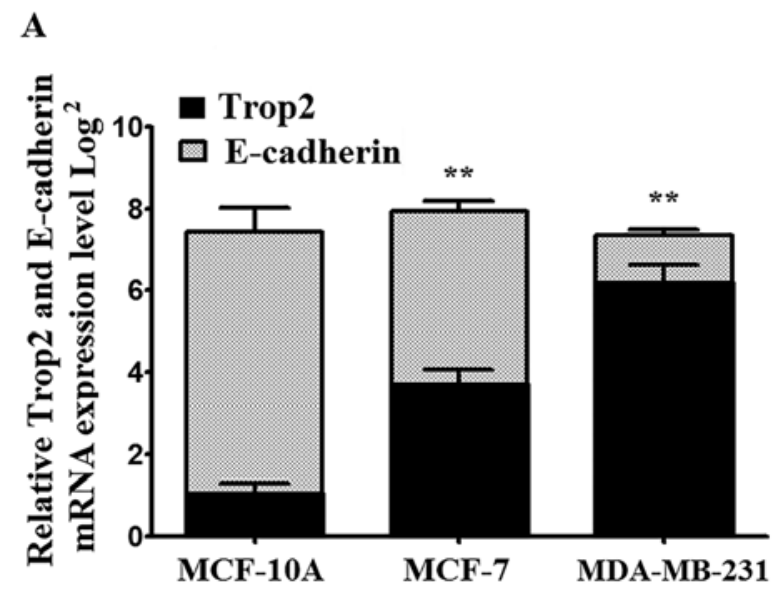

B

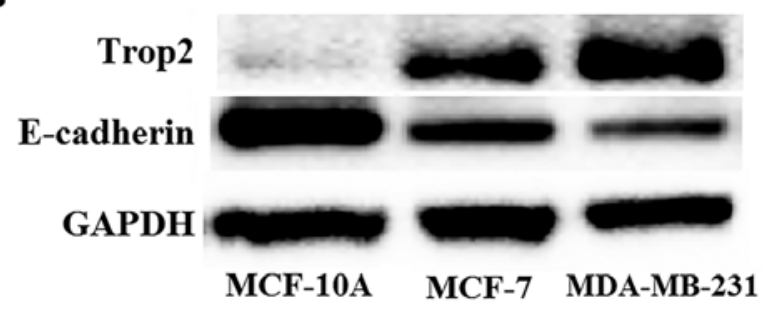

Figure 4. The expression level of Trop2 and E-cadherin mRNA and protein in BC cell lines. (A) The mRNA expression level of relative Trop2 and E-cadherin in MCF-10A, MCF-7 and MDA-MB-231 cells as determined by qRT-PCR; and (B) the protein expression level of Trop2 and E-cadherin in MCF-10A, MCF-7 and MDA-MB-231 cells as determined by western blotting. qRT-PCR, quantitative real-time polymerase chain reaction. $\mathrm{BC}$, breast cancer. ${ }^{* *} \mathrm{P}<0.001$ compared with the MCF-10A group.

$\mathrm{T}^{+} \mathrm{E}^{-}$expression was associated with poor OS (Fig. 3). These results may help in our analysis of the 5-year survival rate of $\mathrm{BC}$ patients. 
Table II. Association of the expression level of Trop2 and E-cadherin with clinicopathological characteristics in BC patients.

\begin{tabular}{|c|c|c|c|c|c|c|c|c|}
\hline Characteristic & $\mathrm{n}$ & $\begin{array}{c}\text { Trop2 } \\
\text { E-cadherin }\end{array}$ & $\begin{array}{l}+ \\
+\end{array}$ & $\begin{array}{l}+ \\
-\end{array}$ & $\begin{array}{l}- \\
+\end{array}$ & - & Pearson $x^{2}$ & P-value \\
\hline Total & 295 & & & & & & 38.089 & $<0.001^{\mathrm{a}}$ \\
\hline Tumor location & & & & & & & 0.493 & 0.920 \\
\hline Left & 180 & & $16(8.9)$ & $105(58.3)$ & $47(26.1)$ & $12(6.7)$ & & \\
\hline Right & 115 & & $13(11.3)$ & $65(56.5)$ & $30(26.1)$ & $7(6.1)$ & & \\
\hline Age (years) & & & & & & & 0.819 & 0.845 \\
\hline Premenopausal & 88 & & $7(8.0)$ & $51(58.0)$ & $25(28.4)$ & $5(5.7)$ & & \\
\hline Postmenopausal & 207 & & $22(10.6)$ & $119(57.5)$ & $52(25.1)$ & $14(6.8)$ & & \\
\hline Tumor size $(\mathrm{cm})$ & & & & & & & 4.417 & 0.620 \\
\hline$\leq 2$ & 57 & & $5(8.8)$ & $29(50.9)$ & $19(33.3)$ & $4(7.0)$ & & \\
\hline$>2$ and $\leq 5$ & 227 & & $23(10.1)$ & $136(59.9)$ & $54(23.8)$ & $14(6.2)$ & & \\
\hline$>5$ & 10 & & $0(0.0)$ & $5(50)$ & $4(40.0)$ & $1(10.0)$ & & \\
\hline \multicolumn{9}{|l|}{ ER } \\
\hline Positive & 126 & & $16(12.7)$ & $67(53.2)$ & $36(28.6)$ & $7(5.6)$ & 3.378 & 0.337 \\
\hline Negative & 169 & & $12(7.7)$ & $103(60.9)$ & $41(24.3)$ & $12(7.1)$ & & \\
\hline PR & & & & & & & 6.823 & 0.078 \\
\hline Positive & 122 & & $17(13.9)$ & $65(53.3)$ & $29(23.8)$ & $11(9.0)$ & & \\
\hline negative & 173 & & $12(6.9)$ & $105(60.7)$ & $48(27.7)$ & $8(4.6)$ & & \\
\hline HER2 & & & & & & & 8.485 & $0.037^{\mathrm{a}}$ \\
\hline Positive & 108 & & $8(7.4)$ & $74(68.5)$ & $20(18.5)$ & $6(5.6)$ & & \\
\hline Negative & 187 & & $21(11.2)$ & $96(51.3)$ & $57(30.5)$ & $13(7.0)$ & & \\
\hline Ki-67 & & & & & & & 5.864 & 0.118 \\
\hline Positive & 275 & & $25(9.1)$ & $162(58.9)$ & $5(25.0)$ & $16(5.8)$ & & \\
\hline Negative & 20 & & $4(13.8)$ & $8(40.0)$ & $72(26.2)$ & $3(15.0)$ & & \\
\hline \multicolumn{9}{|l|}{ Lymph node status } \\
\hline No & 187 & & $20(10.7)$ & $129(69.0)$ & $27(14.4)$ & $8(7.4)$ & 38.688 & $<0.001^{\mathrm{a}}$ \\
\hline $\mathrm{N} 1+2+3$ & 108 & & $9(8.3)$ & $41(38.0)$ & $50(46.3)$ & $11(5.9)$ & & \\
\hline \multicolumn{9}{|l|}{ Metastasis } \\
\hline M0 & 182 & & $18(9.9)$ & $132(72.5)$ & $23(12.6)$ & $9(4.9)$ & 42.958 & $<0.001^{\mathrm{a}}$ \\
\hline M1 & 113 & & $11(9.7)$ & $38(33.6)$ & $54(47.8)$ & $10(8.8)$ & & \\
\hline \multicolumn{9}{|l|}{ TNM stage } \\
\hline 1 & 124 & & $16(12.9)$ & $60(48.4)$ & $37(29.8)$ & $11(8.9)$ & 15.91 & $0.014^{\mathrm{b}}$ \\
\hline 2 & 97 & & 8 (8.2) & $68(70.1)$ & $15(15.5)$ & $6(6.2)$ & & \\
\hline 3 & 74 & & $5(6.8)$ & $42(57.6)$ & $25(33.8)$ & $2(2.7)$ & & \\
\hline TNBC & & & & & & & 10.429 & $0.015^{\mathrm{b}}$ \\
\hline Positive & 199 & & $22(11.1)$ & $102(51.3)$ & $61(30.7)$ & $14(7.0)$ & & \\
\hline Negative & 96 & & 7 (7.3) & $68(70.8)$ & $16(16.7)$ & $5(5.2)$ & & \\
\hline
\end{tabular}

${ }^{\mathrm{a}} \mathrm{P}<0.001,{ }^{\mathrm{b}} \mathrm{P}<0.05 . \mathrm{BC}$, breast cancer; ER, estrogen receptor; progesterone receptor; TNM, tumor-node-metastasis; TNBC, triple negative breast cancer.

Trop2 and E-cadherin $m R N A$ and protein expression in $B C$ cell lines. To better demonstrate the level of Trop2 and $\mathrm{E}$-cadherin expression in $\mathrm{BC}$, we assessed the protein level of Trop2 and E-cadherin in two types of BC cell lines (MCF-7 and MDA-MB-231) and the human breast epithelial cell line MCF-10A. Trop2 expression was the lowest and E-cadherin was the highest in the MCF-10A cells when compared with the BC cell lines. The MCF-7 and MDA-MB-231 cell lines exhibited increased Trop2 and decreased E-cadherin expression levels when compared with MCF-10A cells as determined by qRT-PCR and western blot assay (Fig. 4). 
Table III. Univariate and multivariate analysis of prognostic markers for overall survival in breast cancer.

\begin{tabular}{|c|c|c|c|c|c|c|}
\hline & \multicolumn{3}{|c|}{ Univariate analysis } & \multicolumn{3}{|c|}{ Multivariate analysis } \\
\hline & HR & $\mathrm{P}<|\mathrm{Z}|$ & $95 \% \mathrm{CI}$ & HR & $\mathrm{P}<\mathrm{ZZ|}$ & $95 \% \mathrm{CI}$ \\
\hline \multicolumn{7}{|l|}{ Trop2 and E-cadherin } \\
\hline $\mathrm{T}^{+} \mathrm{E}^{+}$vs. $\mathrm{T}^{+} \mathrm{E}^{+}$vs. $\mathrm{TE}^{-}$vs. TE+ & 1.656 & $0.001^{\mathrm{a}}$ & $1.241-2.209$ & 1.743 & 0.037 & $0.518-2.066$ \\
\hline \multicolumn{7}{|l|}{ Location } \\
\hline Left vs. right & 1.107 & 0.699 & $0.663-1.848$ & & & \\
\hline \multicolumn{7}{|l|}{ Age (years) } \\
\hline Premenopausal vs. postmenopausal & 1.027 & 0.924 & $0.597-1.767$ & & & \\
\hline \multicolumn{7}{|l|}{ Tumor size $(\mathrm{cm})$} \\
\hline$\leq 2$ vs. $>2$ and $\leq 5$ vs. $>5$ & 0.823 & 0.273 & $0.580-1.166$ & & & \\
\hline \multicolumn{7}{|l|}{ ER } \\
\hline Positive vs. negative & 0.993 & 0.977 & $0.619-1.594$ & & & \\
\hline \multicolumn{7}{|l|}{ PR } \\
\hline Positive vs. negative & 0.819 & 0.382 & $0.502-1.042$ & & & \\
\hline \multicolumn{7}{|l|}{ HER 2} \\
\hline Positive vs. negative & 2.192 & 0.092 & $0.919-1.309$ & & & \\
\hline \multicolumn{7}{|l|}{ Ki-67 } \\
\hline Positive vs. negative & 0.732 & 0.398 & $0.492-1.382$ & & & \\
\hline \multicolumn{7}{|l|}{ Lymph node status } \\
\hline N0 vs. N1+2+3 & 11.11 & $<0.001^{\mathrm{a}}$ & $5.118-24.124$ & 3.264 & $0.014^{\mathrm{a}}$ & $1.276-8.348$ \\
\hline \multicolumn{7}{|l|}{ Metastasis } \\
\hline M0 vs. M1 & 10.29 & $<0.001^{\mathrm{a}}$ & $4.193-19.729$ & 5.151 & $0.001^{\mathrm{a}}$ & $3.789-14.091$ \\
\hline \multicolumn{7}{|l|}{ TNM stage } \\
\hline 1 vs. 2 vs. 3 & 2.134 & $<0.001^{\mathrm{a}}$ & $1.723-2.634$ & 1.592 & 0.062 & $0.983-1.869$ \\
\hline \multicolumn{7}{|l|}{ TNBC } \\
\hline Positive vs. negative & 3.921 & $<0.001^{\mathrm{a}}$ & $2.732-5.823$ & 3.029 & $<0.001^{\mathrm{a}}$ & $1.823-6.032$ \\
\hline
\end{tabular}

${ }^{\mathrm{a}} \mathrm{P}<0.05$. HR, hazard ratio; CI, confidence interval; ER, estrogen receptor; progesterone receptor; TNM, tumor-node-metastasis; TNBC, triple negative breast cancer.

\section{Discussion}

The invasion and metastasis of tumors refers to the process of tumor cells being transferred to other tissues from the original site (23-25). EMT is a developmental process in which epithelial cells lose their phenotypes, such as E-cadherin and $\mathrm{N}$-cadherin, and mesenchymal cells gain their phenotypes, such as vimentin and fibronectin. EMT is considered to be important in the invasive and metastasis progression of cancer (26). EMT promotes migration and invasion, accelerates stem cell properties, conduces immunosuppression, and deters apoptosis and senescence (20). Both Trop2 and E-cadherin have a great influence on EMT transformation.

In our previous study (unpublished data), we confirmed that Trop2 upregulated the expression of the mesenchymal phenotype and downregulated the epithelial phenotype, such as E-cadherin and $\mathrm{N}$-cadherin. We also demonstrated that Trop2 was involved in $\beta$-catenin/TGF- $\beta 1$-mediated EMT in gastric cancer. Lin et al (27) have revealed that Trop2 is highly expressed in $\mathrm{BC}$ patients and it is related to the expression level of cyclin D1. However, the potential role of Trop2 in the promotion of EMT in BC has not been fully studied.

In the present study, Trop 2 mRNA was highly expressed in BC tissues while E-cadherin mRNA was decreased in $\mathrm{BC}$ tissues compared with those in matched para-carcinoma tissues, results which were similar to a previous study (20). Notably, we also found that the Trop2 and E-cadherin mRNA expression levels in the TNBC tissues were $2.76 \pm 0.77$ and $0.54 \pm 0.21$ fold higher than those in other types of BC. A similar result was found in protein expression. Our TMA results also revealed that the Trop $2^{+} / \mathrm{E}^{- \text {cadherin }}{ }^{-}$expression was associated with lymph node status, metastasis, TNM stage and ER/PR $/$ HER2- Furthermore, a high Trop2/low E-cadherin expression predicted poor OS in BC patients. Lastly, we detected Trop2 and E-cadherin expression in $\mathrm{BC}$ cell lines (MCF-7 and MDA-MB-231) and the normal breast epithelial cell line MCF-10A, and we found that Trop2 had a higher expression while E-cadherin had a lower level compared with that in the normal breast epithelial cell line. 
Different expression of Trop2/E-cadherin between cancer tissues and adjacent tissues indicate that high Trop2/low E-cadherin expression is connected with $\mathrm{BC}$ or even TNBC. Our findings revealed that Trop2 promoted the migration and invasion of $\mathrm{BC}$ cells by inducing the EMT phenomenon, resulting in lymph node involvement and distant metastasis which always indicates poor prognosis and short OS. The function of E-cadherin does the opposite in BC.

Overall, high Trop2 and low E-cadherin expression may predict poor prognosis and short survival in BC. Furthermore, Trop2 and E-cadherin could be considered as therapeutic targets. In the future, more studies should be performed to confirm the mechanism of Trop2 and E-cadherin in vivo and in vitro.

\section{Acknowledgements}

We thank all the patients enrolled in the study.

\section{Funding}

The present study was supported by grants from the 'Six Talent Peaks Project' in Jiangsu Province (no. WSN-068) and the National Natural Science Foundation of China (no. 81601618).

\section{Availability of data and materials}

The datasets used during the present study are available from the corresponding author upon reasonable request.

\section{Authors' contributions}

WBH and YCZ designed the study; WZ, XWK and XYZ acquired the data and drafted the article; LZJ, JSW and XBY analyzed and interpreted the data; ZDT, XLW, QL and BW revised the article critically for important intellectual content. All authors read and approved the manuscript and agree to be accountable for all aspects of the research in ensuring that the accuracy or integrity of any part of the work are appropriately investigated and resolved.

\section{Ethics approval and consent to participate}

The study protocal was approved by the Human Research Ethic Committee of Nanjing First Hospital. Written informed consent was obtained before the patients underwent surgery.

\section{Patient consent for publication}

Not applicable.

\section{Competing interests}

The authors declare that they have no competing interests.

\section{References}

1. Ferlay J, Soerjomataram I, Dikshit R, Eser S, Mathers C, Rebelo M, Parkin DM, Forman D and Bray F: Cancer incidence and mortality worldwide: Sources, methods and major patterns in GLOBOCAN 2012. Int J Cancer 136: E359-E386, 2015.
2. Zeichner SB, Terawaki $\mathrm{H}$ and Gogineni $\mathrm{K}$ : A review of systemic treatment in metastatic triple-negative breast cancer. Breast Cancer (Auckl) 10: 25-36, 2016.

3. Abdel-Fatah TMA, Agarwal D, Liu DX, Russell R, Rueda OM, Liu K, Xu B, Moseley PM, Green AR, Pockley AG, et al: SPAG5 as a prognostic biomarker and chemotherapy sensitivity predictor in breast cancer: A retrospective, integrated genomic, transcriptomic, and protein analysis. Lancet Oncol 17: 1004-1018, 2016.

4. Cetin I and Topcul M: Triple negative breast cancer. Asian Pac J Cancer Prev 15: 2427-2431, 2014.

5. Park YH, Jung HH, Ahn JS and Im YH: Statin induces inhibition of triple negative breast cancer (TNBC) cells via PI3K pathway. Biochem Biophys Res Commun 439: 275-279, 2013.

6. Ma CX, Cai S, Li S, Ryan CE, Guo ZF, Schaiff WT, Lin L, Hoog J, Goiffon RJ, Prat A, et al: Targeting Chk1 in p53-deficient triple-negative breast cancer is therapeutically beneficial in human-in-mouse tumor models. J Clin Invest 122: 1541-1552, 2012.

7. Jitariu AA, Cimpean AM, Ribatti D and Raica M: Triple negative breast cancer: The kiss of death. Oncotarget 8: 46652-46662, 2017.

8. Zhao W, Zhu H, Zhang S, Yong H, Wang W, Zhou Y, Wang B, Wen J, Qiu Z, Ding G, et al: Trop2 is overexpressed in gastric cancer and predicts poor prognosis. Oncotarget 7: 6136-6145, 2016.

9. McDougall AR, Tolcos M, Hooper SB, Cole TJ and Wallace MJ: Trop2: From development to disease. Dev Dyn 244: 99-109, 2015.

10. Li Z, Jiang X and Zhang W: TROP2 overexpression promotes proliferation and invasion of lung adenocarcinoma cells. Biochem Biophys Res Commun 470: 197-204, 2016.

11. Cubas R, Zhang S, Li M, Chen C and Yao Q: Trop2 expression contributes to tumor pathogenesis by activating the ERK MAPK pathway. Mol Cancer 9: 253: 2010.

12. Guerra E, Trerotola M, Dell' Arciprete R, Bonasera V, Palombo B, El-Sewedy T, Ciccimarra T, Crescenzi C, Lorenzini F, Lorenzini F, et al: A bicistronic CYCLIN D1-TROP2 mRNA chimera demonstrates a novel oncogenic mechanism in human cancer. Cancer Res 68: 8113-8121, 2008.

13. Wu Y, Zhang L, Zhang L, Wang Y, Li H, Ren XB, Wei F, Yu WW, Liu T, Wang X, et al: Long non-coding RNA HOTAIR promotes tumor cell invasion and metastasis by recruiting EZH2 and repressing E-cadherin in oral squamous cell carcinoma. Int J Oncol 46: 2586-2594, 2015.

14. Bai ZT, Wu ZR, Xi LL, Li X, Chen P, Wang FQ, Meng WB, Zhou WC, Wu XA, Yao XJ, et al: Inhibition of invasion by $\mathrm{N}$-trans-feruloyloctopamine via AKT, p38MAPK and EMT related signals in hepatocellular carcinoma cells. Bioorg Med Chem Lett 27: 989-993, 2017.

15. Yang Y, Zhang J, Yan Y, Cai H, Li M, Sun K, Wang J, Liu X, Wang $J$ and Duan X: Low expression of Rap1GAP is associated with epithelial-mesenchymal transition (EMT) and poor prognosis in gastric cancer. Oncotarget 8: 8057-8068, 2017.

16. Cong N, Du P, Zhang A, Shen F, Su J, Pu P, Wang T, Zjang J, Kang $C$ and Zhang Q: Downregulated microRNA-200a promotes EMT and tumor growth through the wnt/ $\beta$-catenin pathway by targeting the E-cadherin repressors ZEB1/ZEB2 in gastric adenocarcinoma. Oncol Rep 29: 1579-1587, 2013.

17. He R, Zhang FH and Shen N: LncRNA FEZF1-AS1 enhances epithelial-mesenchymal transition (EMT) through suppressing E-cadherin and regulating WNT pathway in non-small cell lung cancer (NSCLC). Biomed Pharmacother 95: 331-338, 2017.

18. Zhang J, Chen XY, Huang KJ, Wu WD, Jiang T, Cao J, Zhou LS, Qiu ZJ and Huang C: Expression of FoxM1 and the EMT-associated protein E-cadherin in gastric cancer and its clinical significance. Oncol Lett 12: 2445-2450, 2016.

19. Wang ZS, Shen Y, Li X, Zhou CZ, Wen YG, Jin YB and Li JK: Significance and prognostic value of Gli-1 and Snail/E-cadherin expression in progressive gastric cancer. Tumour Biol 35: $1357-1363,2014$.

20. Chandra Mangalhara K, Manvati S, Saini SK, Ponnusamy K, Agarwal G, Abraham SK and Bamezai RNK: ERK2-ZEB1-miR-101-1 axis contributes to epithelial-mesenchymal transition and cell migration in cancer. Cancer Lett 391: 59-73, 2017.

21. Ahmed NS, Ghatak S, El Masry MS, Gnyawali SC, Roy S, Amer M, Everts H, Sen CK and Khanna S: Epidermal E-Cadherin dependent $\beta$-catenin pathway is phytochemical inducible and accelerates anagen hair cycling. Mol Ther 25: 2502-2512, 2017. 
22. Garcia-Pedrero JM, Garcia-Cabo P, Ángeles Villaronga M, Hermida-Prado F, Granda-Diaz R, Allonca E and Rodrigo JP: Prognostic significance of E-cadherin and $\beta$-catenin expression in HPV-negative oropharyngeal squamous cell carcinomas. Head Neck 39: 2293-2300, 2017.

23. Kalluri R and Weinberg RA: The basics of epithelial-mesenchymal transition. J Clin Invest 119: 1420-1428, 2009.

24. Su SC, Hsieh MJ, Yang WE, Chung WH, Reiter RJ and Yang SF: Cancer metastasis: Mechanisms of inhibition by melatonin J Pineal Res 62: 2017.
25. Pearlman RL, Montes de Oca MK, Pal HC and Afaq F: Potential therapeutic targets of epithelial-mesenchymal transition in melanoma. Cancer Lett 391: 125-140, 2017.

26. Hao Y, Yang X, Zhang D, Luo J and Chen R: Long noncoding RNA LINC01186, regulated by TGF- $\beta$ /SMAD3, inhibits migration and invasion through Epithelial-Mesenchymal-Transition in lung cancer. Gene 608: 1-12, 2017.

27. Lin H, Zhang H, Wang J, Lu M, Zheng F, Wang C, Tang X, $\mathrm{Xu} \mathrm{N}$, Chen R, Zhang D, et al: A novel human Fab antibody for Trop2 inhibits breast cancer growth in vitro and in vivo. Int $\mathbf{J}$ Cancer 134: 1239-1249, 2014. 